\title{
Research on Seismic Analysis of Converter Valve of Offshore Flexible High Voltage Direct Current Considering the Effect of Initial Displacement
}

\author{
Lihong Zhang ${ }^{1 *}$, Jin Xiao ${ }^{2}$, Wei Lv ${ }^{1}$ and Di Zeng ${ }^{1}$ \\ ${ }^{1}$ China Institute of Water Resources and Hydropower Research, Beijing, 100048, China \\ ${ }^{2}$ XJ Group Corporation, Xuchang, Henan, 461000, China
}

\begin{abstract}
Due to the acceleration of global energy transformation and the reduction of the cost of new energy, offshore wind power has been attached great importance by many countries. Therefore, offshore wind power transmission based on flexible HVDC transmission technology has become a hot issue in the development and research of offshore wind power. When the offshore platform is running for a long time, there may be extreme conditions of encountering earthquake. As the core component of flexible HVDC transmission, converter valve's structural safety research under earthquake is very necessary. Different from the onshore converter station and limited by the installation environment, the bottom support insulator of offshore converter valve tower may have initial displacement after being installed on the foundation plate of offshore platform. However, there is no literature on the effect of initial displacement on the dynamic characteristics and seismic performance of valve towers. In this paper, a practical engineering valve tower is taken as an example. Firstly, the influence of different initial displacements on the dynamic characteristics of valve tower is studied. Then, the dynamic analysis of valve tower under earthquake load is carried out by using time history integration algorithm. The influence of initial displacement on the structural safety of valve tower is studied by comparison method. The results of this paper can provide reference for similar projects.
\end{abstract}

\section{Introduction}

With the acceleration of global energy transformation and the reduction of new energy costs, countries rich in marine resources gradually attach importance to the development of offshore wind power[1]. Offshore wind power has the advantages of not occupying land resources, high efficiency of wind energy utilization and strong stability of wind resources. Especially with the large-scale offshore wind turbine, the expansion of investment scale and the decline of construction cost, offshore wind power generation is highly valued by all countries in the world, and has become one of the fastest growing renewable energy sources in the world. At present, China's offshore wind power has entered a period of rapid development[2].

As a new type of DC transmission system, flexible DC transmission can independently control the active and reactive power, provide synchronous $\mathrm{AC}$ power for wind farms, and have strong fault ride through capability. It can be used as a way for large-scale, long-distance offshore wind farms to connect to the land power grid[3,4]. Converter station is the leader of flexible HVDC transmission system, and converter valve is the core component of converter station. The operation of converter valve is closely related to the stable operation of the whole flexible direct current system. The offshore converter station is affected by waves and strong wind for a long time, and even encounter more extreme situations such as earthquake. Therefore, the structural safety of converter valve tower, especially under the action of earthquake load, is very important.

According to the different fixed methods, the converter valve can be divided into two types: supported valve tower and suspended valve tower. In foreign countries, suspended converter valves with better seismic performance are often used in offshore flexible DC transmission projects. However, the flexible HVDC projects which have been put into operation and under construction in China all adopt the supported type converter valve, and there is no suspended converter valve design scheme[5]. The supported valve tower is easy to install, and the strength requirement of the valve hall roof is not high, but the requirement for the strength and flatness of the valve hall ground foundation is high[6]. In order to improve the anti-seismic capability of the supported converter valve, some suppliers add diagonal insulators between the support insulators. The diagonal insulator has the nonlinear characteristic that it can only bear the tension but not the pressure[7].

Because the installation of valve tower in offshore converter station is limited by construction technology and site, the bottom support insulator may sink to different degrees after installation, which is called the initial 
displacement, which leads to the initial stress in the valve tower structure system. The influence of initial stress on the natural frequency and other dynamic characteristics of beams and trusses systems has been concerned and studied by many scholars[8-12]. For the supported valve, few scholars and engineers have paid attention to the effect of initial displacement on its dynamic characteristics, and similarly, the seismic performance of converter valve has not been considered in the existing literatures [7, 13-16].

In this paper, the valve tower installed in an offshore flexible HVDC transmission project is taken as the research object. Firstly, the influence of initial displacement of different amplitude on the dynamic characteristics of valve tower is investigated. Secondly, the dynamic analysis of the valve tower with and without initial displacement under seismic load is carried out by using the time integration algorithm, and the influence of the initial displacement on the dynamic response of the valve tower is studied. Finally, the seismic performance of the valve is evaluated.

\section{Valve tower and finite element model}

In this paper, the converter valve tower used for flexible HVDC transmission is a layered double row supporting structure. The valve tower is composed of four layers of components, with a total weight of about 70 tons. In order to improve the seismic capacity, in addition to the arrangement of support insulators at the bottom and between layers of valve tower, the staggered network structure is composed of diagonal insulators, which is composed of insulator pieces in series, and can only bear tension but not pressure. Figure 1 shows the finite element model of the valve tower in this simulation. The valve tower is about $8.9 \mathrm{~m}$ long, $5.2 \mathrm{~m}$ wide and $11.7 \mathrm{~m}$ high.

The support insulator, module beam, connecting aluminum beam and other components are simulated by beam element, and the diagonal insulator is simulated by nonlinear spring, whose stiffness in the tensile stress area is determined according to the material properties and section of the insulator, while the spring stiffness in the compressive stress area is set as about 0 . The material properties of each component in the valve tower finite element model are shown in Table 1. In the actual project, after the valve tower is installed, the overall inclination rate of the valve tower is about $5.3 \%$. The initial displacement value of the bottom of each supporting insulator is shown in Table 2, and the negative sign in the table indicates subsidence.

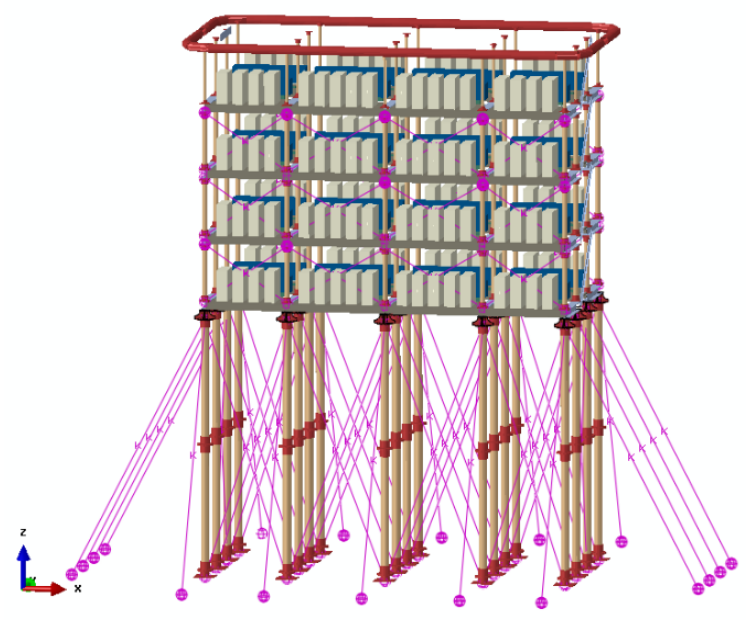

Figure 1. Finite element model of the converter valve

Table 1. Material properties of the main components.

\begin{tabular}{ccccc}
\hline Material Name & $\begin{array}{c}\text { Elastic modulus } \\
(\mathrm{GPa})\end{array}$ & Poisson's ratio & $\begin{array}{c}\text { Density } \\
\left(\mathrm{kg} / \mathrm{m}^{3}\right)\end{array}$ & $\begin{array}{c}\text { Allowable stress } \\
(\mathrm{MPa})\end{array}$ \\
\hline Aluminum beam & 71 & 0.34 & 2800 & 270 \\
Insulation beam & 17.6 & 0.34 & 2000 & 100 \\
Diagonal insulator & 25 & 0.34 & 1800 & 550 \\
Support insulator & 25 & 0.34 & 1800 & 155 \\
\hline
\end{tabular}

Table 2. Initial displacement values of the bottom support insulators (unit: $\mathrm{cm}$ ).

\begin{tabular}{|c|c|c|c|c|c|}
\hline Location & $\begin{array}{c}\text { Long axis } \\
\text { direction station 1 }\end{array}$ & $\begin{array}{c}\text { Long axis } \\
\text { direction station 2 }\end{array}$ & $\begin{array}{c}\text { Long axis } \\
\text { direction station 3 }\end{array}$ & $\begin{array}{c}\text { Long axis } \\
\text { direction station 4 }\end{array}$ & $\begin{array}{c}\text { Long axis } \\
\text { direction station 5 }\end{array}$ \\
\hline $\begin{array}{c}\text { Short axis direction } \\
\text { station 1 }\end{array}$ & 0.00 & -0.17 & -0.15 & -0.22 & 0.00 \\
\hline $\begin{array}{c}\text { Short axis direction } \\
\text { station 2 }\end{array}$ & -0.07 & -0.14 & -0.12 & -0.29 & -0.17 \\
\hline $\begin{array}{c}\text { Short axis direction } \\
\text { station 3 }\end{array}$ & -0.03 & -0.21 & -0.18 & -0.36 & -0.23 \\
\hline $\begin{array}{c}\text { Short axis direction } \\
\text { station 4 }\end{array}$ & 0.00 & -0.18 & -0.15 & -0.33 & -0.30 \\
\hline
\end{tabular}




\section{Influence of initial displacement on dynamic characteristics of valve tower}

In order to study the influence of initial displacement on the dynamic characteristics of valve tower, the modal analysis of valve tower without initial displacement, 1 times of initial displacement, 2 times of initial displacement and 4 times of initial displacement is carried out in this paper. Table 3 shows the first 10 modal frequencies of valve tower. The first mode is translational

along the short axis of the valve tower, the second mode is rotating in the plane, and the third mode is translational along the long axis of the valve tower. Figure 2 shows the relative difference percentage of natural frequencies of valve tower considering different amplitude initial displacement compared with the case without initial displacement. It can be seen that the initial displacement has little influence on the low-order frequency, especially the frequency of the first 18 orders. For the higher-order frequency, such as 18-45 order, with the increase of the initial displacement amplitude, the valve tower frequency gradually decreases.

Table 3. The first 20 frequencies of the converter valve tower (unit: $\mathrm{Hz}$ ).

\begin{tabular}{|c|c|c|c|c|}
\hline $\begin{array}{c}\text { Mode } \\
\text { number }\end{array}$ & $\begin{array}{c}\text { no initial } \\
\text { displacement }\end{array}$ & $\begin{array}{c}\text { 1 times of initial } \\
\text { displacement }\end{array}$ & $\begin{array}{c}\text { 2 times of initial } \\
\text { displacement }\end{array}$ & $\begin{array}{c}4 \text { times of initial } \\
\text { displacement }\end{array}$ \\
\hline 1 & 1.2855 & 1.2858 & 1.2860 & 1.2864 \\
\hline 2 & 1.7330 & 1.7330 & 1.7330 & 1.7327 \\
\hline 3 & 1.7797 & 1.7772 & 1.7746 & 1.7694 \\
\hline 4 & 2.6676 & 2.6651 & 2.6624 & 2.6560 \\
\hline 5 & 5.0767 & 5.0754 & 5.0738 & 6.0697 \\
\hline 6 & 6.2622 & 6.2601 & 6.2575 & 6.2509 \\
\hline 7 & 6.4867 & 6.4868 & 6.4867 & 6.4862 \\
\hline 8 & 8.2582 & 8.2568 & 8.2552 & 8.2515 \\
\hline 9 & 9.4836 & 9.4834 & 9.4831 & 9.4817 \\
\hline 10 & 9.7565 & 9.7551 & 9.7533 & 9.7485 \\
\hline
\end{tabular}

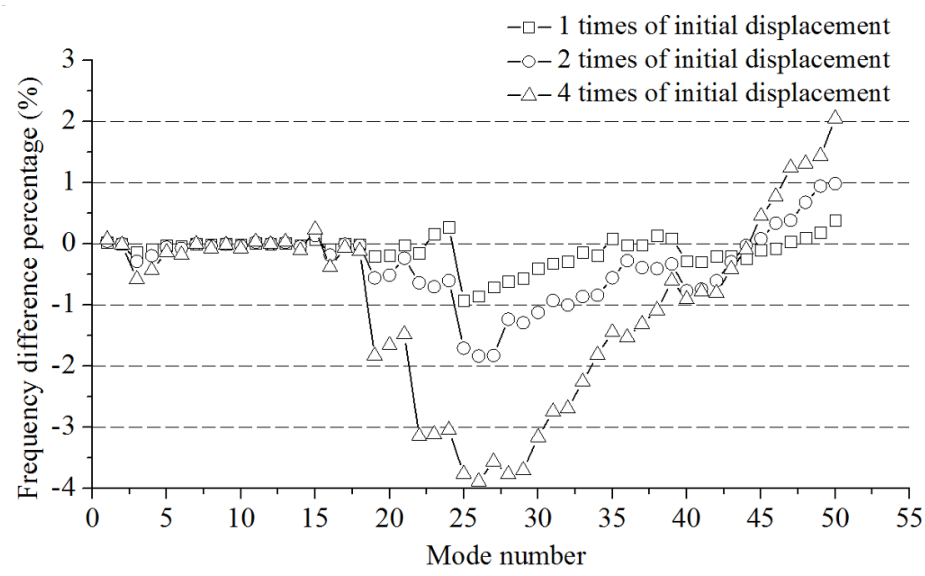

Figure 2. Relative difference percentage of natural frequencies of valve tower

\section{Transient dynamic results}

\subsection{Seismic load}

When the converter valve tower operates on offshore platform for a long time, there may be some extreme conditions such as earthquake disaster. In order to investigate the influence of the initial displacement on the seismic performance of the valve tower, the dynamic analysis is carried out for the valve tower with and without the initial displacement. The seismic wave input from the bottom of the support insulator is shown in figure 3 . 


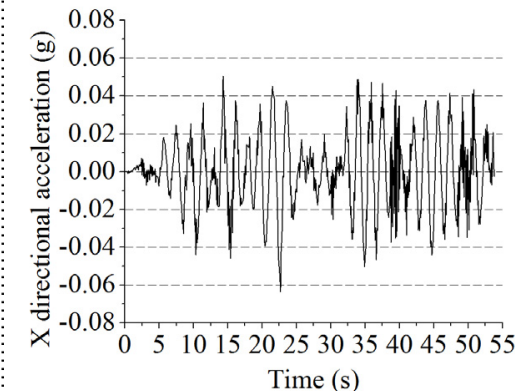

(a) $\mathrm{X}$ direction

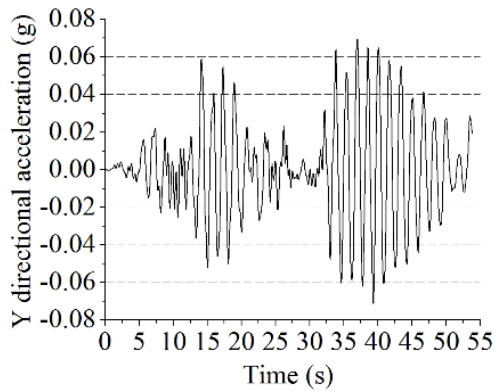

(b) Y direction

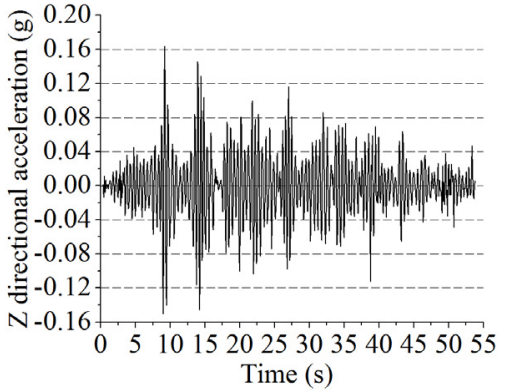

(c) $\mathrm{Z}$ direction

Figure 3. Acceleration time history curve of seismic wave

In the seismic analysis, two working conditions are considered: $1.0 \times$ gravity $+1.0 \times \mathrm{X}$ direction earthquake + $1.0 \times \mathrm{Z}$ direction earthquake $(\mathrm{X}+\mathrm{Z}$ for short $)$ and $1.0 \times$ gravity $+1.0 \times \mathrm{Y}$ direction earthquake $+1.0 \times \mathrm{Z}$ direction earthquake ( $\mathrm{Y}+\mathrm{Z}$ for short). The $\mathrm{X}$ direction is the long side direction of the valve tower, the $\mathrm{Y}$ direction is the short side direction of the valve tower, and the $\mathrm{Z}$ direction is the vertical direction.

Because the diagonal insulator has the nonlinear characteristics of tension and incompressibility, the response spectrum method based on linear superposition principle is not applicable. Therefore, this paper uses Newman - $\beta$ time history integration algorithm to solve the dynamic problem. In addition, the Rayleigh damping matrix is used to determine the damping coefficient of the whole structure.

\subsection{Displacement results}

The maximum displacement and acceleration of the valve tower under earthquake load appear on the corona ring at the top of the valve tower. The specific calculation results are shown in Table 4. It can be seen that the displacement response of valve tower considering the initial displacement is larger than that without considering the initial displacement. For the acceleration response results, the acceleration response under $\mathrm{X}+\mathrm{Z}$ condition without considering the initial displacement is greater, but for $\mathrm{Y}+\mathrm{Z}$ condition, the acceleration response considering the initial displacement is greater.

Table. 4 The maximun displacement and acceleration of the valve

\begin{tabular}{|c|c|c|c|c|c|c|c|c|c|}
\hline & \multicolumn{4}{|c|}{ Displacement (unit: cm) } & \multicolumn{3}{c|}{ Acceleration (unit: g) } \\
\hline Working condition & \multicolumn{2}{|c|}{$\mathrm{X}+\mathrm{Z}$} & \multicolumn{2}{c|}{ Y+Z } & \multicolumn{3}{c|}{ Y+Z } \\
\hline Initial displacement & With & Without & With & Without & With & Without & With & Without \\
\hline X directional & 1.94 & 1.91 & 0.45 & 0.22 & 0.144 & 0.175 & 0.045 & 0.025 \\
\hline Y directional & 0.35 & 0.27 & 5.03 & 4.03 & 0.002 & 0.020 & 0.231 & 0.152 \\
\hline Z directional & 0.13 & 0.06 & 0.19 & 0.08 & 0.166 & 0.167 & 0.166 & 0.167 \\
\hline
\end{tabular}

\subsection{Stress results}

The maximum stress response results of key components of valve tower under seismic wave are shown in Table 5.
The stress results of most members are slightly larger when the initial displacement is considered. Generally speaking, the stress results of metal materials are not more than their allowable stress, which meets the material strength requirements in code GB 50260[17].

Table. 5 Maximum stress of key components of valve tower (unit: MPa)

\begin{tabular}{|c|c|c|c|c|}
\hline & \multicolumn{2}{|c|}{$\mathrm{X}+\mathrm{Z}$} & \multicolumn{2}{c|}{ Y+Z } \\
\hline Initial displacement & With & Without & With & 13.95 \\
\hline Aluminum beam & 31.41 & 10.27 & 38.74 & 5.40 \\
\hline Insulation beam & 10.62 & 7.53 & 6.37 & 126.0 \\
\hline Diagonal insulator & 106.2 & 90.4 & 154.4 & 54.7 \\
\hline Support insulator & 23.96 & 26.0 & 76.33 & \\
\hline
\end{tabular}

\section{Conclusions}

According to the numerical simulation results, the following conclusions can be drawn:

(1) The initial installation displacement of offshore valve tower has an impact on the natural frequency of the structure, especially for the higher-order frequency above 18. With the increase of initial displacement, the influence is more obvious.

(2) The initial displacement also has influence on the displacement, acceleration and stress of the valve tower under seismic load. Generally speaking, the dynamic 
response of the case with initial displacement is larger than that without initial displacement.

(3) In conclusion, the effect of initial displacement on the dynamic characteristics and seismic performance of valve tower structure can not be ignored. Therefore, in the process of offshore platform construction, attention should be paid to the flatness control of valve tower installation platform to minimize the initial displacement value.

\section{Acknowledgments}

The authors acknowledge financial supports from the National Natural Science Foundation of China (Grant No.51679265), IWHR Research \& Development Support Program (EB0145B412016).

\section{References}

1. Shi, Z.Y., Wang, C.X., Li, Q.H. (2015) Research on Key Issues of China's Offshore Wind Power Development in the "14th Five-Year Plan". Electric Power, 53: 8-17.

2. Huang, H.L., Hu, Z.L., Dai, W.B., et al. (2020) Development Status and Trend of Offshore Wind Power. Energy and Energy Conservation, 6: 51-53.

3. Huang, Z.Q., Chen, B., Zhou, M. (2016) Offshore Wind Power Transmission Engineering Technology and Application. China Water Conservancy and Hydropower Press, Beijing.

4. Xu Z. (2016) Flexible HVDC transmission system. China Machine Press, Beijing.

5. Hao, W.H., Zhou, Y. (2019) Research on the Selection of Key Electrical Equipments in Offshore VSC-HVDC Converter Station. Southern Energy Construction, 2019, 6(01):31-35

6. Wang, D.L., Han. J.H., Li, Y.Z., et al. (2018) Research on UHVDC Transmission and Construction of Converter Valve. Shandong electric power, 45: 78-80.

7. Gao, B., Zhang, W.W., Yu, H.B., et al. (2018) Anti seismic design of a supported converter valve tower. Machine Design and Manufacturing Engineering, 47: 35-39.

8. Dong, C.J., Liu, S.Z., Li, A.J. (2018) Influence of prestressing force on dynamic characteristics of simply supported prestressed concrete beam. Journal of Lanzhou Jiaotong University, 37(05):13-17.

9. Wang, L.L. (2013) Analysis of Prestressing Effect on Natural Frequency for Simply Supported Beam. Phd thesis. Jilin University, Jilin.

10. Xiao, J.T., Wu, H.L. (2010) Prestress Force Effect on Natrual Frequencies of Simply Supported Prestressed Beams. Science Technology and Engineering, 10: 2909-2912+2919.

11. Lin, J., (2005) Theoretical and Experimental research on Sunflower-patterned Large-span Spatial Cabletruss Tensile Structures. Phd thesis. Zhejiang University, Hangzhou.

12. Zhang, J.W., Sun, L., Zhang, X.Y., et al. (2019) Effect of initial stresses and deformations on the natural frequencies of beams. Journal of Vibration and Shock, 38: 46-51.

13. Enblom, R., Coad, J.N.O., Berggren, S. (1993) Design of HVDC converter station equipment subject to severe seismic performance requirements. IEEE Transactions on Power Delivery, 8(4):1766-1772.

14. Larder, R.A., Gallagher, R.P., Nilsson, B. (1989) Innovative seismic design aspects of the Intermountain Power Project Converter Stations. IEEE Transactions on Power Delivery, 4(3):17081714.

15. Nakagaki, S., Uchida, T., Koyama, M., et al. (1991) Studies on aseismic measure for multistage thyristor valves. Power Delivery IEEE Transactions on, 6:1819-1824.

16. Zhu, X.H., Zhang, C., Xie, Y.L., et al. (2014) Research on Anti-seismic Performance of IGBT valves of Flexible HVDC. China Electric Power (Technology Edition), 08: 19-22.

17. Ministry of Construction of China. (2013) GB50260 - 2013 Code for seismic design of electrical installation. China Planning Press, Beijing. 